Research Article

\title{
Efficacy of Transdermal Oxybutynin in the Treatment of Overactive Bladder Syndrome: Does It Make Sense Using It in 2017?
}

\author{
Raúl Vozmediano-Chicharro $\mathbb{D}^{1},{ }^{1}$ Blanca Madurga, ${ }^{2}$ and Pedro Blasco ${ }^{3}$ \\ ${ }^{1}$ Department of Urology, Hospital Regional de Málaga, Hospital Civil, University of Malaga, Plz Hospital Civil s/n, \\ 29009 Malaga, Spain \\ ${ }^{2}$ Department of Urology, Hospital Universitario Puerta del Mar, Av. Ana de Viya 21, 11009 Cadiz, Spain \\ ${ }^{3}$ Department of Urology, Hospital Universitario de Valme, Ctra. de Cádiz Km. 548.9, 41014 Seville, Spain
}

Correspondence should be addressed to Raúl Vozmediano-Chicharro; vozme@msn.com

Received 10 May 2018; Accepted 5 July 2018; Published 29 July 2018

Academic Editor: Matthew Rutman

Copyright (c) 2018 Raúl Vozmediano-Chicharro et al. This is an open access article distributed under the Creative Commons Attribution License, which permits unrestricted use, distribution, and reproduction in any medium, provided the original work is properly cited.

\begin{abstract}
Objectives. Evaluation of changes in symptoms among patients with overactive bladder syndrome treated with transdermal oxybutynin and tolerability after 12 months of follow-up. Methods. This was a multicenter, retrospective, single-cohort, observational study. Changes in symptoms were evaluated primarily with a 3-day voiding diary. Results were compared to baseline. Subgroup analyses were performed in patients previously treated for OAB or not and aged $<65$ years versus $\geq 65$ years. Results. Clinical records of 105 patients were examined; 92.4\% were women. At 12 months, 58 patients continued to receive transdermal oxybutynin. Changes in symptoms according to the voiding diary were evaluated in 47 patients. Significant improvements from baseline were observed in urinary frequency $(-2.6$ voids/24 hours $(95 \%$ CI: $-3.5 ;-1.8), p<0.001)$; daily number of urgent episodes $(-4.7$ episodes/day (95\% CI: $-6.1 ;-3.6), p<0.001)$; and urge incontinence $(-1.9$ episodes/day $(95 \%$ CI: $-2.9 ;-1.3)$, $p<0.001)$. No statistically significant differences were found in subgroup analyses. In total, $38.1 \%$ of patients had adverse events, primarily in the application site (27.6\%). No severe systemic adverse events occurred. Only 6 patients (5.7\%) reported dry mouth. Conclusions. Improved symptoms and good tolerability observed after 1 year of treatment with transdermal oxybutynin shows that it currently has a place in the treatment of $\mathrm{OAB}$ patients.
\end{abstract}

\section{Introduction}

Overactive bladder syndrome $(\mathrm{OAB})$ has been clinically defined as urinary urgency, with or without incontinence, generally accompanied by an increase in urinary frequency and nocturia, after any local disease or metabolic disorder that would explain these symptoms has been ruled out [1]. According to the EPIC study in 2009, the prevalence of overactive bladder and/or urinary incontinence in Spain reached $54 \%$ in subjects over the age of 65 [2]. The number of individuals with $\mathrm{OAB}$ is expected to increase in successive years as the population ages.

Despite the benefits of antimuscarinics in $\mathrm{OAB}$ treatment $[3,4]$, oral administration causes well-known side effects, in particular dry mouth, often leading patients to discontinue treatment and tolerate their incontinence [5]. Administration of transdermal oxybutynin (OXY-TDS) was approved by the Spanish Medicine Agency in 2004. Transdermal delivery has been shown to significantly reduce side effects by decreasing the active metabolite of oxybutynin (N-DEO) involved in their onset, thus possibly improving treatment adherence [6]. The efficacy and safety of OXYTDS in the treatment of $\mathrm{OAB}$ have been established in several clinical trials [7-9].

Although randomized clinical trials are still the gold standard, generalization of results from these studies may be limited by widely varying mid- and long-term responses in real-world situations, lack of treatment adherence, or the use 
of drugs in patients with diverse morbidities. Therefore, the aim of this study was to ascertain if the improvement in symptoms and good tolerability shown in clinical trials are reproduced under clinical practice conditions.

\section{Methods}

The Oxybutynin-transdermal in Standard ClinicAl pRactice study (OSCAR study) was a retrospective cohort study in clinical practice conditions. Clinical records of patients with a diagnosis of OAB who received OXY-TDS in 3 centers in the same Spanish health-care region were reviewed. Data were collected at baseline, before starting treatment with OXY-TDS, and at 6 and 12 months of treatment. Adult patients of both sexes with a diagnosis of $\mathrm{OAB}$ according to their clinical records and a 3-day voiding diary (3 DVD) who had started treatment with OXY-TDS at least 12 months before inclusion in the study were enrolled. The study was conducted in accordance with the ethical requirements of the Declaration of Helsinki and Good Clinical Practice guidelines and approved by the Provincial Research Ethics Committee of Malaga.

The primary objective was to evaluate changes in symptoms in OAB patients receiving OXY-TDS after 12 months of treatment. Tolerability to OXY-TDS was also evaluated.

Changes in symptoms were evaluated using the 3 DVD as the primary tool. Parameters included in the 3 DVD are shown in Table 1. The urgency visual analogue scale (VAS) was a 10-point Likert-type scale, the OAB-V8 scale for detection of symptomatic $\mathrm{OAB}[10]$, and the Spanish validation of the International Consultation on Incontinence Questionnaire-Short Form (ICIQ-SF) [11] were also used. Tolerability was evaluated from adverse events recorded, percentage of treatment interruptions, and reasons for discontinuation.

Subgroup analyses were also performed to compare changes in 3 DVD parameters among patients treated (nonnaive) versus not previously treated (naive) with OXYTDS for $\mathrm{OAB}$ and patients aged less than 65 years versus 65 years or more.

Sample size was based on an alpha risk of $5 \%$ and a statistical power of $80 \%$ for comparing 24-hour urinary frequency pre- and posttreatment with OXY-TDS. A minimum of 118 subjects were estimated to be necessary for detecting statistically significant differences around $10 \%$ between baseline and end of the treatment. A baseline voiding frequency of 11 was assumed, along with a standard deviation of 4 .

The primary statistical analysis was based on a comparison of clinical outcomes between the OXY-TDS pre- and posttreatment periods (baseline versus 12 months) in patients who completed the study correctly (per protocol analysis). The baseline status was also compared with status after 6 months of OXY-TDS treatment to evaluate an interim response between the different study parameters.

Data were described by counts and percentages, mean and standard deviation, or median and minimum and maximum, as appropriate. Pre- to posttreatment results were compared by paired $t$-test, Wilcoxon's signed rank test, McNemar's test, or the McNemar-Bowker marginal homogeneity chi-squared test, as appropriate.

Statistical tests were performed using SPSS version 20.0 (IBM SPSS, Inc., Chicago, IL, USA) and Stats Direct software (V.2.s8).

\section{Results}

Clinical records of 105 patients who met the study selection criteria were evaluated. Figure 1 shows the study flow chart. All patients included in the study were Caucasian, $92.4 \%$ were women $(7.62 \%$ men). Age was 59.4 (11.8) (mean and SD) years, and body mass index was 26.8 (4.4). Time since onset of $\mathrm{OAB}$ before treatment with OXY-TDS was 4.10 (4.9) years. The most common clinical antecedents were depression in 18 patients (17.1\%) and surgical interventions for urinary incontinence in 19 patients (18.1\%). Overall, of the patients for whom data was available, 66 patients $(66.7 \%)$ had received previous treatment for $\mathrm{OAB}$ before starting OXY-TDS. Anticholinergics were the most common, followed by beta- 3 agonists, and in both cases, the most common reason for discontinuation was lack of efficacy, although adverse events were also a very common cause of discontinuation of anticholinergics. All previous treatments were discontinued before the start of OXY-TDS except for 1 patient who was taking a beta-3 agonist.

After 6 months of treatment, 63 patients (60.0\%) continued to receive OXY-TDS, 45 of whom provided 3 DVD data. Reductions were observed in the number of daytime, night-time, and 24-hour urinary episodes, number of episodes of urgency and urgency grade, and the number of changes of underwear or protective pads. All these changes were statistically significant.

Twelve months after initiating treatment, 58 patients (55.2\%) continued to receive OXY-TDS. Complete 3 DVD data were available at 12 months from 47 of 58 patients (81.0\%). Statistically significant improvements from baseline were observed in the number of voids, both during the day and at night, in the number of daily urinary urgency and urgent urinary episodes and in urinary urgency grade. Statistically significant changes were also observed in the number of times a patient needed a change of underwear or absorbent pads (Table 1). A total of 33 patients $(70.2 \%)$ presented more than 4 episodes of urgency/day at baseline, and this proportion fell to 2 of 47 patients or $4.2 \%$ after 12 months of treatment with OXY-TDS $(p<0.001)$.

Although all patients completed the urgency VAS $(N=58)$ at 12 months, the evaluation of the 3 DVD completed by patients $(N=47)$ showed a statistically significant improvement from baseline $(-4.50$ points (95\% CI: -5.50 ; $-4.00), p<0.001)$. The difference in the mean ICIQ-SF scale at baseline and after 12 months of treatment was -8 points $(95 \%$ CI: $-10.0 ;-6.5, p=0.000$ ) (Table 2 ), while on OAB-V8, the difference in score was -13.5 (95\% CI: $-16.0 ;-11.5, p<0.001)$.

No statistically significant differences were observed in any of the 3 DVD variables at 12 months of treatment between patients who were not previously treated for $\mathrm{OAB}$ (naive) and patients who had been treated (nonnaive). Nor 
TABLE 1: Changes from pre- to posttreatment in 3 DVD parameters after 12 months of OXY-TDS treatment.

\begin{tabular}{|c|c|c|c|c|c|c|}
\hline \multirow{2}{*}{3 DVD parameters } & \multicolumn{2}{|c|}{ Pretreatment } & \multicolumn{2}{|c|}{ Posttreatment } & \multirow{2}{*}{ Change (95\% CI) } & \multirow{2}{*}{$p$ value } \\
\hline & $N$ & $M(\mathrm{SD})$ & $N$ & $M(\mathrm{SD})$ & & \\
\hline DUF (episodes/day)* & 47 & $9.1(3.1)$ & 46 & $7.0(1.6)$ & $-1.7(-2.55 ;-1.15)$ & $<0.001$ \\
\hline NUF (episodes/night)* & 47 & $1.6(1.4)$ & 44 & $0.8(0.8)$ & $-0.9(-1.12 ;-0.45)$ & $<0.001$ \\
\hline $\mathrm{UF} / 24 \mathrm{~h}$ (episodes/day)* & 47 & $10.7(3.9)$ & 47 & $7.7(1.8)$ & $-2.6(-3.50 ;-1.80)$ & $<0.001$ \\
\hline Maximum UV $(\mathrm{ml})^{*}$ & 38 & $250.7(107.8)$ & 39 & $346.0(278.5)$ & $63.3(19.95 ; 105.85)$ & 0.006 \\
\hline Nocturnal UV (ml) & 38 & $146.6(134.1)$ & 39 & $134.2(147.7)$ & $-16.2(-81.65 ; 48.35)$ & 0.651 \\
\hline Mean UV (ml) & 5 & $134.8(83.4)$ & 5 & $202.6(47.9)$ & $0.8(-22.30 ; 20.70)$ & 0.976 \\
\hline Urgency (episodes/day) & 47 & $7.0(4.7)$ & 47 & $1.5(1.5)$ & $-4.7(-6.05 ;-3.55)$ & $<0.001$ \\
\hline Urgency grade* & 47 & $3.7(0.5)$ & 44 & $2.3(1.3)$ & $-1.4(-1.85 ;-0.85)$ & $<0.001$ \\
\hline UUI (episodes/day)* & 46 & $2.7(2.7)$ & 43 & $0.5(0.9)$ & $-1.9(-2.85 ;-1.30)$ & $<0.001$ \\
\hline SUI (episodes/day)* & 47 & $0.7(1.2)$ & 47 & $0.2(0.5)$ & $0.0(-0.85 ; 0.00)$ & 0.007 \\
\hline $\mathrm{Pad} /$ underwear changes (number/day) ${ }^{*}$ & 40 & $3.4(4.1)$ & 45 & $0.7(1.1)$ & $-2.2(-2.80 ;-1.50)$ & $<0.001$ \\
\hline Liquid intake $/ 24 \mathrm{~h}(\mathrm{ml})$ & 38 & $1435.1(406.1)$ & 38 & $1453.5(518.9)$ & $15.8(-134.15 ; 179.95)$ & 0.698 \\
\hline Urine output/24h (ml) & 38 & $1385.9(381.2)$ & 39 & $1504.4(381.1)$ & $115.9(0.00 ; 223.35)$ & $0.054^{* *}$ \\
\hline Nocturnal urine output (ml) & 37 & $200.8(161.5)$ & 38 & $174.7(202.4)$ & $-30.9(-107.50 ; 34.20)$ & 0.51 \\
\hline
\end{tabular}

3 DVD: 3-day voiding diary; DUF: daytime urinary frequency; NUF: night-time urinary frequency; UF/24 h: 24-hour urinary frequency (total number of episodes/24 hours); SUI: stress urinary frequency; UV: urinary volume; UUI: urge urinary frequency. $p$ values: Student's $t$-test or *Wilcoxon signed rank test. Change: mean difference or *Hodges-Lehman estimator of location shift. ${ }^{* *}$ This variable was not reported in the 6-month visit in any of the evaluable cases. For this reason, no statistical comparisons were performed.

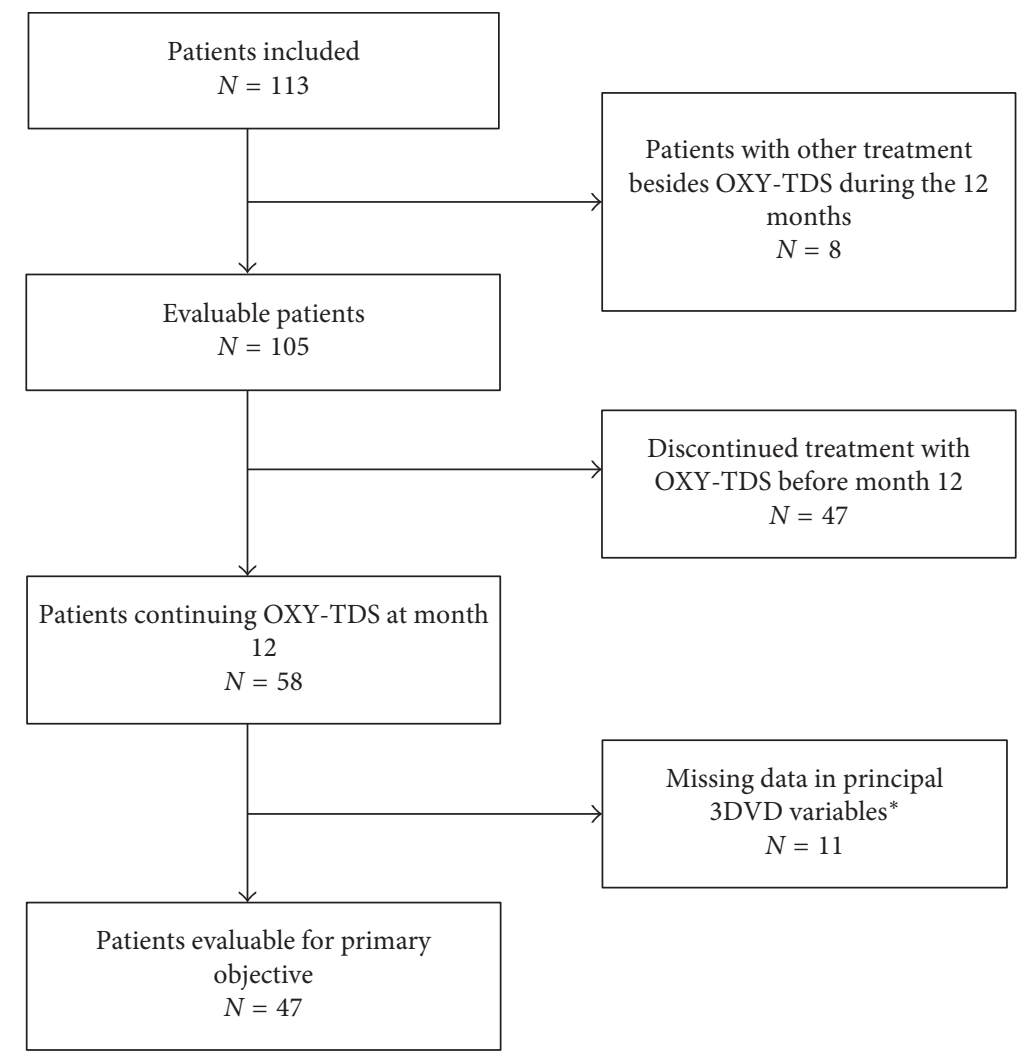

Figure 1: Study flow chart. Patients evaluated for study objectives according to data collected in clinical records. * Frequency, urgency, and urge incontinence. OXY-TDS: transdermal oxybutynin. 3 DVD: 3-day voiding diary.

were statistically significant differences observed between patients who were younger than 65 years and those who were 65 and older (Tables 3 and 4).

Twelve months after starting treatment, 47 patients (44.8\%) had discontinued treatment. Reasons for discontinuation were adverse events in 18 patients (38.3\%), lack of response in 17 (36.2\%), and lack of treatment compliance in
$4(8.5 \%)$; another reason or no reason was given for 8 (17.0\%) patients.

Regarding tolerability, 40 patients $(38.1 \%)$ had some kind of adverse event at 12 months, mainly at the site of application of the patch (29 patients, $27.6 \%), 16(15.2 \%)$ in the form of pruritus, 4 (3.8\%) with erythema, and 13 (12.4\%) with irritated skin. Two of the local adverse events (skin irritation) 
TABle 2: ICIQ-SF questionnaire. Changes from baseline after 12 months of treatment with OXY-TDS.

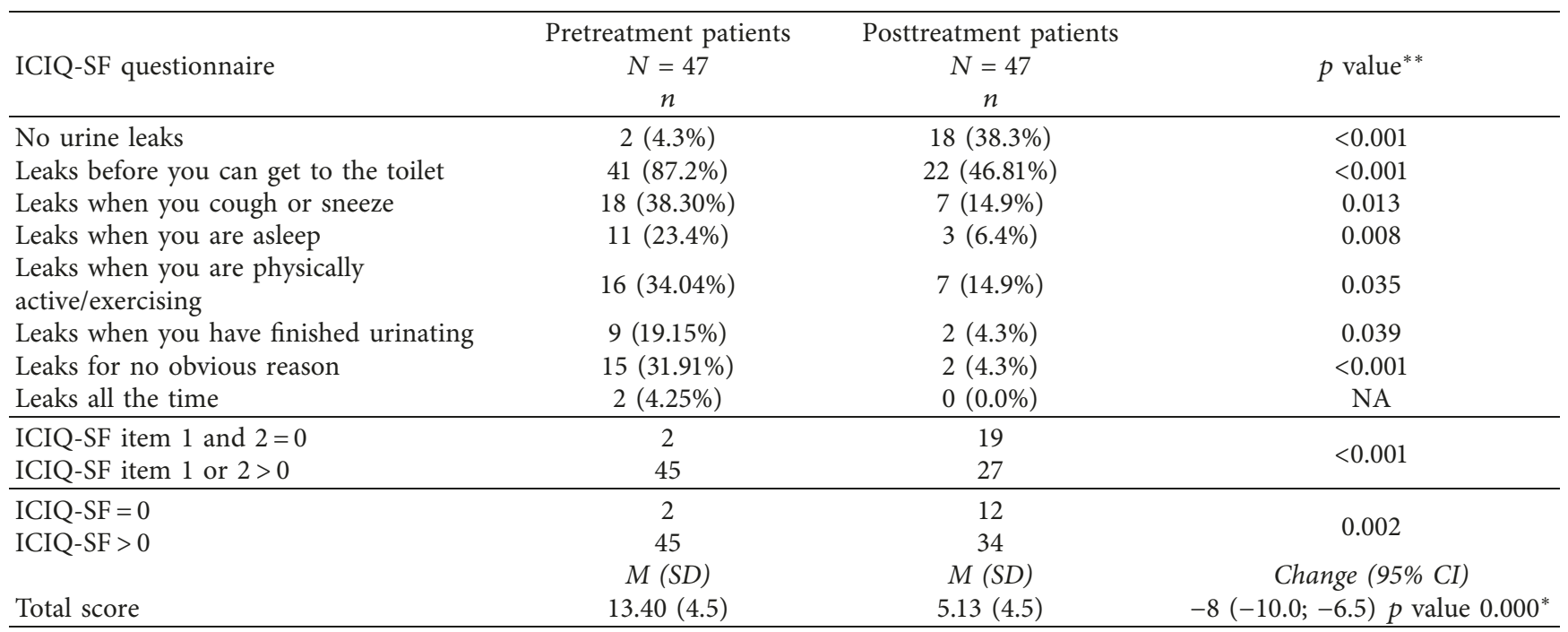

Statistical tests: Student's $t$-test (variables with normal distribution) or Wilcoxon signed rank test ( ${ }^{*}$ variables with nonnormal distribution); ${ }^{* *} \mathrm{McNemar}$.

TABLE 3: Changes 3D from baseline in the 3 DVD tool at 12 months of treatment with OXY-TDS (naive/nonnaive patients).

\begin{tabular}{|c|c|c|c|c|}
\hline 3 DVD & $\begin{array}{l}\text { Naive }(n=15) \\
\text { mean }(S D)\end{array}$ & $\begin{array}{c}\text { Nonnaive }(n=32) \\
\text { mean }(S D)\end{array}$ & Diff $(95 \% \mathrm{CI})$ & $p$ value \\
\hline DUF (episodes/day)* & $7.07(1.8)$ & $6.9(1.5)$ & $0.4(-0.7 ; 1.3)$ & 0.341 \\
\hline NUF (episodes/night) ${ }^{*}$ & $0.87(0.7)$ & $0.7(0.8)$ & $0.0(-3.0 ; 0.7)$ & 0.411 \\
\hline UF/24 hours (episodes/day)* & $8.0(2.1)$ & $7.6(1.7)$ & $6.3(-0.4 ; 1.7)$ & 0.298 \\
\hline Maximum UV (ml)* & $444.6(486.1)$ & $302.1(83.1)$ & $24.1(-41.7 ; 100.0)$ & 0.461 \\
\hline Nocturnal UV (ml) & $112.6(84.9)$ & $143.83(168.9)$ & $-31.2(-135.9 ; 73.5)$ & 0.550 \\
\hline Mean UV (ml) & $205.5(54.9)$ & 191.0 (NA) & $14.5(-180.6 ; 209.6)$ & 0.828 \\
\hline Urgency (episodes/day) & $1.5(2.1)$ & $1.5(1.2)$ & $0.5(-0.9 ; 1.0)$ & 0.892 \\
\hline Urgency grade* & $1.8(1.3)$ & $2.5(1.3)$ & $-0.7(-1.3 ; 0.0)$ & 0.071 \\
\hline UUI (episodes/day)* & $0.2(0.5)$ & $0.6(1.0)$ & $0.0(-0.3 ; 0.0)$ & 0.328 \\
\hline SUI (episodes/day)* & $0.0(0.0)$ & $0.2(0.6)$ & $0.0(0.0 ; 0.0)$ & 0.110 \\
\hline $\mathrm{Pad} /$ underwear changes (number/day) ${ }^{*}$ & $0.6(1.0)$ & $0.8(1.1)$ & $0.0(-0.6 ; 0.0)$ & 0.044 \\
\hline Liquid intake $/ 24 \mathrm{~h}(\mathrm{ml})$ & $1484.73(613.5)$ & $1439.0(481.9)$ & $45.7(-326.4 ; 417.1)$ & 0.805 \\
\hline Urine output/24h (ml) & $1609.17(446.6)$ & $1457.89(347.2)$ & $151.3(-115.5 ; 418.0)$ & 0.258 \\
\hline Nocturnal urine output (ml) & $167.77(138.3)$ & $185.26(228.2)$ & $-17.5(-162.6 ; 127.6)$ & 0.808 \\
\hline
\end{tabular}

3 DVD: 3-day voiding diary; DUF: daytime urinary frequency; NUF: night-time urinary frequency; SD: standard deviation; SUI: stress urinary incontinence; UF/24 h: 24-hour urinary frequency (total number of episodes/24 hours); UUI: urge urinary incontinence. $p$ values: Student's $t$-test or * Wilcoxon signed rank test. Change: mean difference, or ${ }^{*}$ Hodges-Lehman estimator of location shift.

were clinically significant and consequently considered severe. Dry mouth and constipation were recorded in only 6 $(5.7 \%)$ and $1(0.95 \%)$ of the patients, respectively.

\section{Discussion}

In this study, we examined retrospective data from the realworld management of patients with OAB treated with OXYTDS over a 12-month period. Similarly to other studies reported in the literature $[8,9,12,13]$, we found that patients receiving OXY-TDS showed a reduction in OAB symptoms, with statistically significant changes in symptoms according to the 3 DVD, and in the grade of urgency perceived by patients, as recorded on the specific urgency VAS. The combined analysis performed by Dmochowski et al., in particular, found that OXYTDS was more effective than placebo in the reduction of daily incontinence episodes $(-3.0$ versus $-2.0, p=0.0004)$ and daily urinary frequency $(-2.0$ versus $-1.0, p=0.0023)$ [12]. Moreover, OXY-TDS showed reductions similar to other antimuscarinic drugs. Findings from a review of randomized controlled trials with antimuscarinic drugs for $\mathrm{OAB}$ conducted by Novara et al. included reductions in urinary frequency (between -0.7 and -3.69), urgency episodes (between -1.0 and -3.4 ), or urgency urinary incontinence (between -0.3 and -2.28) [3]. It is also important to note that in our study, almost all incontinent patients (4 episodes of urgency/day) before treatment became continent after being treated with OXY-TDS.

In this study, we observed an improvement in symptoms due to OXY-TDS in the first 6 months, which was maintained until the end of the 12-month observational period. This is in line with results from clinical trials, which reported 
TABLE 4: Changes 3D from baseline in the 3 DVD at 12 months of treatment with OXY-TDS (patients $<65$ years and $\geq 65$ years).

\begin{tabular}{|c|c|c|c|c|}
\hline 3 DVD & $\begin{array}{c}<65 \text { years }(n=33) \\
\text { mean }(S D)\end{array}$ & $\begin{array}{c}\geq 65 \text { years }(n=14) \\
\text { mean }(S D)\end{array}$ & Diff $(95 \%$ CI $)$ & $p$ value \\
\hline DUF (episodes/day)* & $6.83(1.5)$ & $7.2(1.9)$ & $-0.3(-1.3 ; 0.7)$ & 0.615 \\
\hline NUF (episodes/night)* & $0.6(0.7)$ & $1.1(0.9)$ & $-0.3(-1.3 ; 0.0)$ & 0.053 \\
\hline $\mathrm{UF} / 24 \mathrm{~h}$ (episodes/day)* & $7.4(1.6)$ & $8.4(2.2)$ & $-0.7(-2.0 ; 0.3)$ & 0.129 \\
\hline Maximum UV $(\mathrm{ml})^{*}$ & $373.5(328.4)$ & $284.0(203.7)$ & $40.0(-26.7 ; 106.7)$ & 0.221 \\
\hline Nocturnal UV (ml) & $107.4(109.2)$ & $194.6(194.4)$ & $-87.2(-188.3 ; 14.0)$ & 0.089 \\
\hline Mean UV (ml) & $205.5(54.9)$ & $191(\mathrm{n} / \mathrm{a})$ & - & - \\
\hline Urgency (episodes/day) & $1.5(1.6)$ & $1.5(1.2)$ & $-0.1(-1.0 ; 0.9)$ & 0.876 \\
\hline Urgency grade* & $2.3(1.3)$ & $2.3(1.4)$ & $0.0(-0.7 ; 0.7)$ & 0.805 \\
\hline UUI (episodes/day)* & $0.3(0.5)$ & $0.87(1.4)$ & $0.0(-0.7 ; 0.0)$ & 0.232 \\
\hline SUI (episodes/day)* & $0.1(0.2)$ & $0.3(0.9)$ & $0.0(0.0 ; 0.0)$ & 0.514 \\
\hline Pad/underwear changes (number/day)* & $0.4(0.6)$ & $1.5(1.5)$ & $-0.7(-2.0 ; 0.0)$ & 0.024 \\
\hline Liquid intake $/ 24 \mathrm{~h}(\mathrm{ml})$ & $1431.2(522.3)$ & $1508.2(531.3)$ & $-77.0(-457.8 ; 303.7)$ & 0.684 \\
\hline Urine output/24h (ml) & $1503.4(377.6)$ & $1506.8(405.3)$ & $-3.4(-274.9 ; 268.1)$ & 0.980 \\
\hline Nocturnal urine output $(\mathrm{ml})$ & $127.0(132.7)$ & $309.2(282.4)$ & $-182.3(-317.7 ; 46.8)$ & 0.063 \\
\hline
\end{tabular}

3 DVD: 3-day voiding diary; DUF: daytime urinary frequency; NUF: night-time urinary frequency; SD: standard deviation; SUI: stress urinary incontinence; UF/24 h: 24-hour urinary frequency (total number of episodes/24 hours); UV: urinary volume; UUI: urge urinary incontinence. $p$ values: Student's $t$-test or ${ }^{*}$ Wilcoxon signed rank test. Change: mean difference or ${ }^{*}$ Hodges-Lehman estimator of location shift.

a response in the early weeks of treatment that was maintained during the following period [6].

Results suggest no differences in response to treatment between patients who were previously treated or treatmentnaive. Similarly, no differences were found between patients younger and older than 65 years of age, but further studies are required to confirm these findings. In this study, approximately half of the patients received previous treatment and continued to present symptoms, and this observation is similar to those of the MATRIX study, despite the current availability of drugs such as solifenacin and mirabegron.

The most troublesome symptoms of $\mathrm{OAB}$ are urgency and urge incontinence [14], which may affect work productivity, impact negatively on quality of life, and lead to depression [15]. Similarly, alleviating OAB symptoms can have a significantly positive effect on health-related quality of life [16]. In this study, the overall improvement in 3 DVD and urgency VAS scores, along with improvements in all domains evaluated in both the ICIQ-SF questionnaire and OAB-V8 scale, affirm that our patients achieved an overall improvement in quality of life. Seventeen percent of our patients had depression, so long-term follow-up studies would be of interest to study associations between improvements in $\mathrm{OAB}$ symptoms and improvements in depressive syndromes.

VAS is a widely accepted research tool for measuring the impact of a disease and the effects of medical interventions on quality of life and has also been useful in urinary incontinence studies. It has been used for both evaluating the effects of urinary incontinence treatments and estimating the subjective perception of the patient with regard to their urinary incontinence $[15,17,18]$. In this study, the urgency VAS tool demonstrated its ability to measure treatment response. More completed urgency VAS scales $(N=58)$ than completed 3 DVDs3D $(N=47)$ were available in the patients' clinical records, and this might be interpreted as greater acceptance of the urgency VAS tool by patients, due to its simplicity as a measure of perceived grade of incontinence. Although 3 DVD is the reference instrument in clinical trials, in clinical practice, it is very difficult for patients to use. However, the urgency VAS may be a transparent, simple-to-use instrument that is easy for the clinician to interpret.

In our study, dry mouth occurred at a rate of $5.7 \%$, less prevalent than expected in the Summary of Product Characteristics [19] (8.6\%) and with other antimuscarinic drugs. In the review by Novara et al., the adverse event of dry mouth was between $13 \%$ and $86 \%$ depending on the study and antimuscarinic drug [3].

The MATRIX study, a 6-month phase IV trial carried out in the US in patients from urology, primary care, gynecology, and geriatrics departments, evaluated changes in health-related quality of life and work productivity in patients with OAB treated with OXY-TDS and found significant improvements in study parameters, along with good tolerability [20]. Two reviews of oxybutynin concluded that the transdermal formulation is generally well tolerated by $\mathrm{OAB}$ patients, with a low rate of anticholinergic-related adverse events, most of which were local, such as skin irritation at the site of application of the patch $[6,21]$. The transdermal form of oxybutynin may offer a better tolerated therapeutic alternative to patients with $\mathrm{OAB}$ and urge incontinence in the management of their symptoms and thus may improve treatment adherence by patients $[5,20,22]$.

In line with the MATRIX study [20], in which dermatitis, in the form of irritation, redness, and pruritus at the site of application of the patch, occurred in $14.0 \%$ of patients, adverse events related with site of application were also the most common in our study. Neither of the local adverse events (skin irritation) considered severe because of their clinical significance required hospital admission nor they did produce disability; in 1 case, the patient had a history of atopic dermatitis that she had not reported previously.

Treatment adherence with OXY-TDS was high in preapproval clinical trials, in which $86-87.1 \%$ of participating patients completed the entire study treatment period $[8,9]$. In our study, conducted in a standard clinical practice setting, $55.2 \%$ of the patients were continuing treatment at 
12 months. Adverse events and failure to respond as expected were the most common reasons for discontinuation, in line with published reviews [23]. It is important to highlight that the persistence rate achieved in our study is high, and at least as high as that with other treatments options (23.7-66\%), possibly associated with differences in efficacy and tolerability [24-27].

In general, however, adverse events were not serious, and treatment discontinuation could suggest that for many patients, the treatment benefits do not outweigh the drawbacks. Further studies are needed to gain more insight into how patients weigh up the difference between expected response and adverse events and what leads them to decide to maintain or discontinue a certain treatment.

To our knowledge, the OSCAR study is the first realworld study carried out in Europe recruiting patients exclusively from urology departments. In the MATRIX study, a 6-month phase IV trial carried out in the US including patients from different departments, the primary endpoint was changes in quality of life, but the 3 DVD was not used for evaluating effectiveness, even $3 \mathrm{D}$ as a secondary endpoint. The OSCAR study evaluated changes in signs and symptoms at 12 months as a primary endpoint, using a patient urinary diary and the OAB-V8 and ICI-Q questionnaires. In addition, cognitive function, adherence, and satisfaction were evaluated as secondary endpoints.

The limitations of this study are those typical of retrospective cohort studies and include among others bias in patient selection and missing data that might affect the final results. Nevertheless, in order to reduce possible bias, strict criteria were applied to the selection of patients, and data were evaluated for each variable according to the number of patients from whom those data were available. It is probable that patients who continue treatment have better results in terms of improvement of symptoms; however, this study did not evaluate symptoms in patients who discontinued. Another possible limitation is that the 3 participating sites were not randomly selected and results may not reflect the reality observed in other regions of Spain. However, that may be an advantage since all 3 centers belonged to the same health-care region that uses a standardized record system.

In conclusion, in view of the results of OSCAR study, it seems that there is currently an important place for OXYTDS in the treatment of $\mathrm{OAB}$, although further real-life studies should be carried out to extend knowledge of the use and effects of the drug in real practice.

\section{Data Availability}

Access to the clinical data used to support the findings of this study, being derived from hospital medical records, is restricted by the Provincial Research Ethics Committee of Malaga in order to protect patient privacy.

\section{Conflicts of Interest}

The authors declare that they have no conflicts of interest.

\section{Acknowledgments}

This work was funded by the study sponsor (Asociación Gaditana de Investigación Urológica). The authors would like to thank GOC Networking for their advice on statistics, methodology, and manuscript preparation.

\section{References}

[1] P. Abrams, L. Cardozo, M. Fall et al., "The standardisation of terminology of lower urinary tract function: report from the Standardisation Sub-Committee of the International Continence Society," American Journal of Obstetrics and Gynecology, vol. 187, no. 1, pp. 116-126, 2002.

[2] E. Martinez Agullo, J. L. Ruiz Cerda, L. Gomez Perez et al., "Prevalence of urinary incontinence and hyperactive bladder in the Spanish population: results of the EPICC study," Actas Urologicas Españolas, vol. 33, no. 2, pp. 159-166, 2009.

[3] G. Novara, A. Galfano, S. Secco et al., "A systematic review and meta-analysis of randomized controlled trials with antimuscarinic drugs for overactive bladder," European Urology, vol. 54, no. 4, pp. 740-764, 2008.

[4] C. R. Chapple, R. Martinez-Garcia, L. Selvaggi et al., "A comparison of the efficacy and tolerability of solifenacin succinate and extended release tolterodine at treating overactive bladder syndrome: results of the STAR trial," European Urology, vol. 48, no. 3, pp. 464-470, 2005.

[5] G. W. Davila, J. S. Starkman, and R. R. Dmochowski, "Transdermal oxybutynin for overactive bladder," Urologic Clinics of North America, vol. 33, no. 4, pp. 455-463, 2006.

[6] J. Salinas-Casado, M. Esteban-Fuertes, O. Serrano, and J. Galvan, "The value of oxybutynin in transdermal patches for treating overactive bladder," Actas Urológicas Españolas, vol. 39, no. 10, pp. 599-604, 2015.

[7] G. W. Davila, C. A. Daugherty, S. W. Sanders, and TOS Group, "A short-term, multicenter, randomized doubleblind dose titration study of the efficacy and anticholinergic side effects of transdermal compared to immediate release oral oxybutynin treatment of patients with urge urinary incontinence," Journal of Urology, vol. 166, no. 1, pp. 140-145, 2001.

[8] R. R. Dmochowski, G. W. Davila, N. R. Zinner et al., "Efficacy and safety of transdermal oxybutynin in patients with urge and mixed urinary incontinence," Journal of Urology, vol. 168, no. 2, pp. 580-586, 2002.

[9] R. R. Dmochowski, P. K. Sand, N. R. Zinner, M. C. Gittelman, G. W. Davila, and S. W. Sanders, "Comparative efficacy and safety of transdermal oxybutynin and oral tolterodine versus placebo in previously treated patients with urge and mixed urinary incontinence," Urology, vol. 62, no. 2, pp. 237-242, 2003.

[10] K. S. Coyne, T. Zyczynski, M. K. Margolis, V. Elinoff, and R. G. Roberts, "Validation of an overactive bladder awareness tool for use in primary care settings," Advances in Therapy, vol. 22, no. 4, pp. 381-394, 2005.

[11] M. Espuna Pons, P. Rebollo Alvarez, and M. Puig Clota, "Validation of the Spanish version of the international consultation on incontinence questionnaire-short form. A questionnaire for assessing the urinary incontinence," Medicina Clínica, vol. 122, no. 8, pp. 288-292, 2004.

[12] R. R. Dmochowski, V. Nitti, D. Staskin, K. Luber, R. Appell, and G. W. Davila, "Transdermal oxybutynin in the treatment of adults with overactive bladder: combined results of two randomized clinical trials," World Journal of Urology, vol. 23, no. 4, pp. 263-270, 2005. 
[13] O. Yamaguchi, E. Uchida, N. Higo et al., "Efficacy and safety of once-daily oxybutynin patch versus placebo and propiverine in Japanese patients with overactive bladder: a randomized double-blind trial," International Journal of Urology, vol. 21, no. 6, pp. 586-593, 2014.

[14] I. Milsom, S. A. Kaplan, K. S. Coyne, C. C. Sexton, and Z. S. Kopp, "Effect of bothersome overactive bladder symptoms on health-related quality of life, anxiety, depression, and treatment seeking in the United States: results from EpiLUTS," Urology, vol. 80, no. 1, pp. 90-96, 2012.

[15] C. C. Sexton, K. S. Coyne, C. Thompson, T. Bavendam, C. I. Chen, and A. Markland, "Prevalence and effect on healthrelated quality of life of overactive bladder in older Americans: results from the epidemiology of lower urinary tract symptoms study," Journal of the American Geriatrics Society, vol. 59, no. 8, pp. 1465-1470, 2011.

[16] C. J. Kelleher, L. Cardozo, C. R. Chapple, F. Haab, and A. M. Ridder, "Improved quality of life in patients with overactive bladder symptoms treated with solifenacin," BJU International, vol. 95, no. 1, pp. 81-85, 2005.

[17] B. Stach-Lempinen, E. Kujansuu, P. Laippala, and R. Metsanoja, "Visual analogue scale, urinary incontinence severity score and $15 \mathrm{D}$-psychometric testing of three different health-related quality-of-life instruments for urinary incontinent women," Scandinavian Journal of Urology and Nephrology, vol. 35, no. 6, pp. 476-483, 2001.

[18] T. Shamliyan, J. F. Wyman, R. Ramakrishnan, F. Sainfort, and R. L. Kane, "Benefits and harms of pharmacologic treatment for urinary incontinence in women: a systematic review," Annals of Internal Medicine, vol. 156, no. 12, pp. 861-874, W301-10, 2012.

[19] European Medicines Agency, Summary of Product Characteristic of Transdermal Oxybutynin, European Medicines Agency, London, UK, 2009, http://www.ema.europa.eu/docs/es_ES/ document_library/EPAR_-_Product_Information/human/0005 32/WC500040171.pdf.

[20] P. Sand, N. Zinner, D. Newman et al., "Oxybutynin transdermal system improves the quality of life in adults with overactive bladder: a multicentre, community-based, randomized study," BJU International, vol. 99, no. 4, pp. 836-844, 2007.

[21] S. A. Macdiarmid, "The evolution of transdermal/topical overactive bladder therapy and its benefits over oral therapy," Reviews in Urology, vol. 11, no. 1, pp. 1-6, 2009.

[22] G. W. Davila, "Transdermal oxybutynin in the treatment of overactive bladder," Clinical Interventions in Aging, vol. 1, no. 2, pp. 99-105, 2006.

[23] J. S. Benner, M. B. Nichol, E. S. Rovner et al., "Patientreported reasons for discontinuing overactive bladder medication," BJU International, vol. 105, no. 9, pp. 1276-1282, 2010.

[24] C. R. Chapple, J. Nazir, Z. Hakimi et al., "Persistence and adherence with mirabegron versus antimuscarinic agents in patients with overactive bladder: a retrospective observational study in UK clinical practice," European Urology, vol. 72, no. 3, pp. 389-399, 2017.

[25] D. Kato, H. Tabuchi, and S. Uno, "Safety, efficacy, and persistence of long-term mirabegron treatment for overactive bladder in the daily clinical setting: interim (1-year) report from a Japanese post-marketing surveillance study," LUTS: Lower Urinary Tract Symptoms, 2017, In press.

[26] A. S. Wagg, S. Foley, J. Peters, J. Nazir, L. Kool-Houweling, and L. Scrine, "Persistence and adherence with mirabegron vs antimuscarinics in overactive bladder: retrospective analysis of a UK general practice prescription database," International Journal of Clinical Practice, vol. 71, no. 10, article e12996, 2017.

[27] D. Sussman, A. Yehoshua, J. Kowalski et al., "Adherence and persistence of mirabegron and anticholinergic therapies in patients with overactive bladder: a real-world claims data analysis," International Journal of Clinical Practice, vol. 71, no. 3-4, article e12824, 2017. 


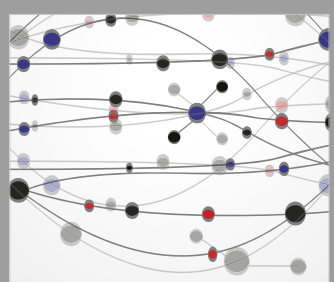

The Scientific World Journal
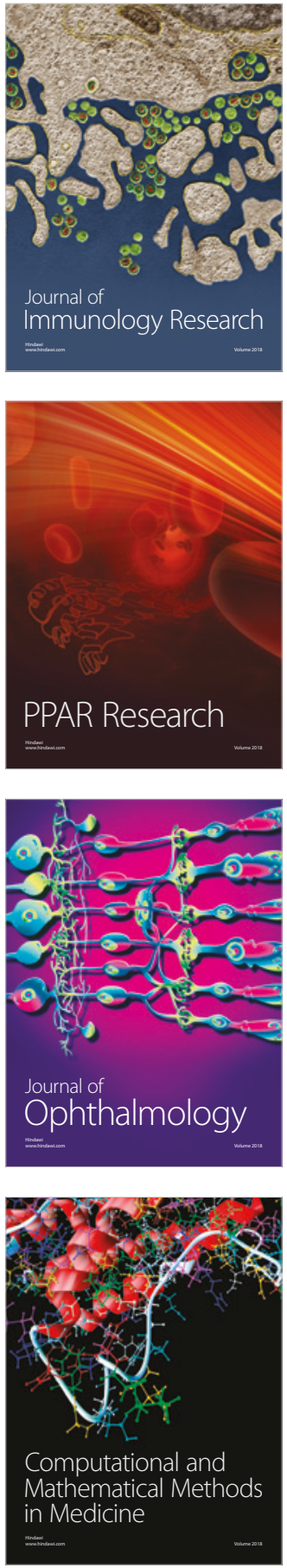

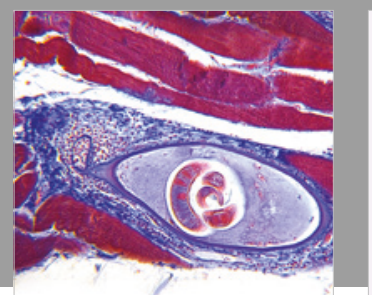

Gastroenterology Research and Practice

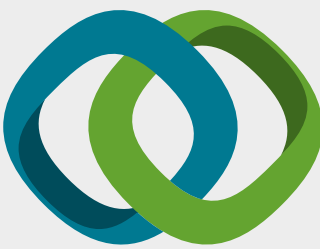

\section{Hindawi}

Submit your manuscripts at

www.hindawi.com
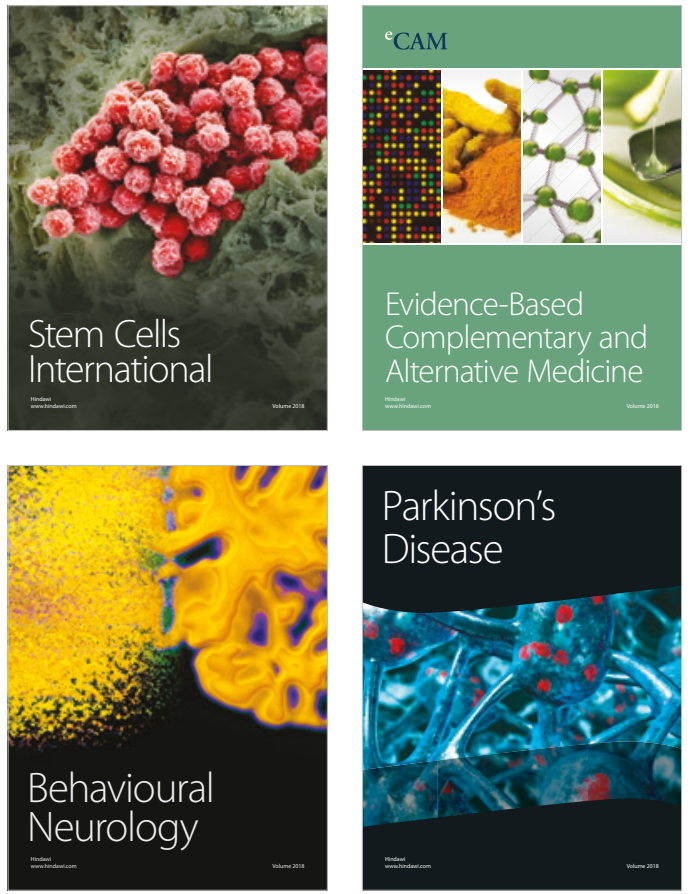

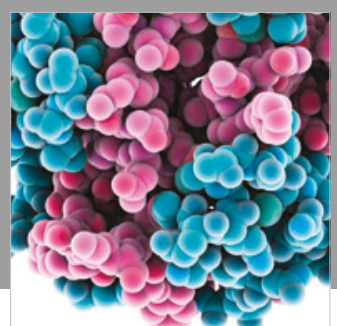

ournal of

Diabetes Research

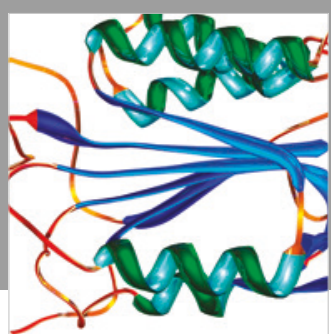

Disease Markers
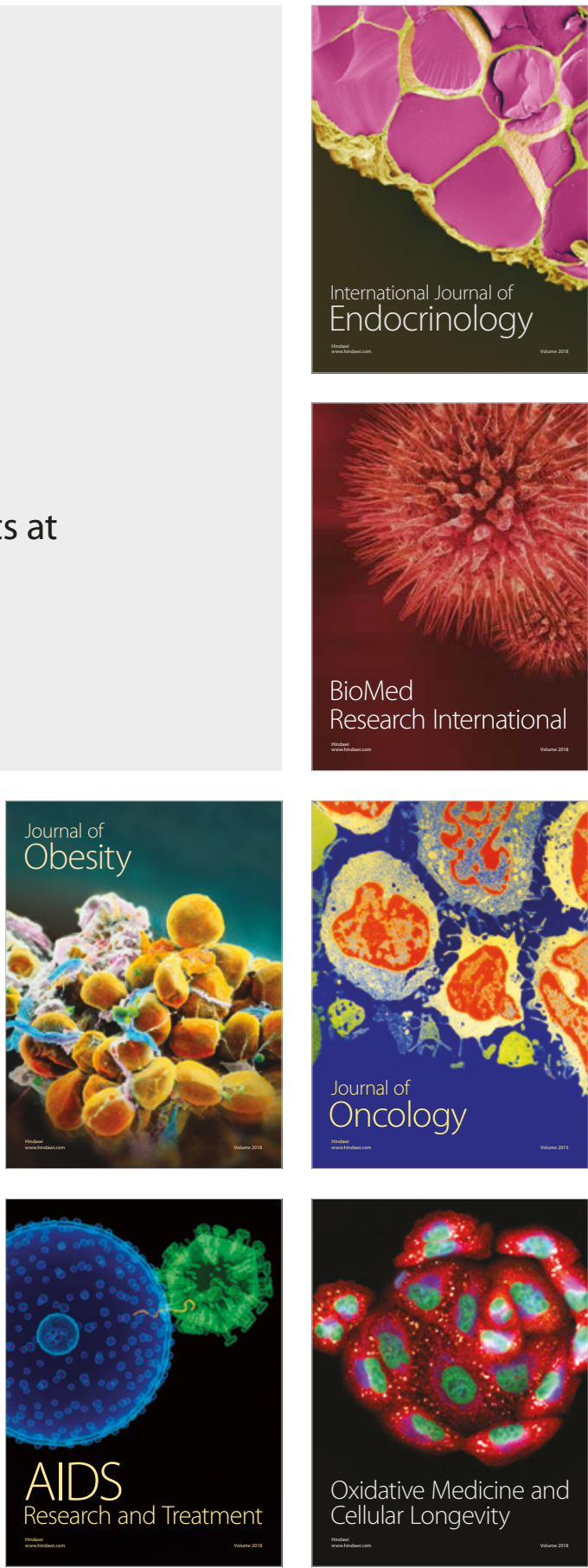